\title{
Revoluções do novo: explosão fragmentária e ajuste de contas ${ }^{1}$
}

Pedro Plaza Pinto ${ }^{2}$

UFPR

1. Este texto tem origem em um dos capítulos da tese "Paulo Emilio e a emergência do Cinema Novo", orientada pelo prof. dr. Ismail Xavier e defendida em 2008 na Escola de Comunicações e Artes da USP.

2. Doutor em Ciências da Comunicação (ECA-USP) e professor do Departamento de História da UFPR (Universidade Federal do Paraná). 
Resumo

Glauber Rocha releu, no final da década de 1970, a importância da crítica de Paulo Emilio Salles Gomes para a sua trajetória. Essa operação contraditória e digressiva seguiu o curso de uma problematização que outros críticos e realizadores do Cinema Novo consideravam evidente: qual é a efetiva presença das concepções críticas de um na atividade criativa e intelectual de outro? A proposta deste texto é considerar essa questão tendo como base as palavras do cineasta, mas também a ressonância das considerações de Paulo Emilio nos textos de Sylvie Pierre e David Neves sobre a figuração glauberiana.

\section{Palavras-chave}

crítica, Salles Gomes, Glauber Rocha

\section{Abstract}

At the end of 1970s, Glauber Rocha rethought the importance of critic Paulo Emilio Salles Gomes on his own trajectory. This complex and digressive examination was part of a critical thinking exercise among a number of Cinema Novo filmmakers and critics. What was the effect of Paulo Emilio Salles Gomes' critical input on the creativity of Glauber Rocha? This question is the primary theme of the paper. To answer it, we would need to consider not only the commentaries of the filmmaker, but also the resonance of Paulo Emilio's ideas on Sylvie Pierre and David Neves' papers about Glauber.

\section{Key-words}

critique, Salles Gomes, Glauber Rocha 


\section{0 testemunho de Sylvie Pierre}

Um comovido depoimento sobre a trajetória e a figuração de Glauber Rocha no cinema e na cultura brasileira, escrito por Sylvie Pierre (1981), foi publicado nas páginas da revista Cahiers du Cinéma no mês de novembro do ano da morte do cineasta. A crítica e estudiosa do cinema brasileiro, uma das divulgadoras do Cinema Novo na Europa, nos legou o precioso testemunho, oscilando entre o relato, a confidência, o comentário e a reflexão sobre o cinema brasileiro moderno, partindo sempre do seu epicentro, "le chef” do Cinema Novo, como diz, para relativizar a própria expressão em seguida. $\mathrm{O}$ tom pessoal domina o arco das afirmações e dos questionamentos que cobrem o período da emergência e do ocaso do alto modernismo cinematográfico, demarcado pela presença do Cinema Novo, sem deixar de lado problemas espinhosos, a exemplo do dissentimento do cineasta com os representantes do "udigrudi", do conturbado retorno ao país nos últimos anos da ditadura militar, do impacto da morte do cineasta. Sem contar, é claro, um olhar sobre os anos da afirmação cinemanovista e sobre a própria figura do cineasta em presença. Entre os momentos de conflito aberto e de solidariedade nas afirmações, o texto sinalizou a possibilidade do coroamento de uma experiência, de acordo com a máxima de que esta só pode se realizar com a extrema proximidade da morte.

Este artigo busca repor, partindo do texto acima referido, a reverberação da presença crítica do intelectual Paulo Emilio Salles 
Gomes nas reavaliações e nos balanços gerados através e a partir da escrita fragmentária e altissonante de Glauber Rocha. Presente em muitos momentos do livro Revolução do Cinema Novo, Paulo Emilio também comparece, referido ou não, quando o crítico e militante do Cinema Novo David Neves interpõe ambas as textualidades, a de Salles Gomes e a do amigo e companheiro que fora uma das mais consideradas lideranças do Cinema Novo.

O texto de Sylvie Pierre inicia as suas observações com a indicação do momento e do local a partir dos quais se tornara amiga de Glauber Rocha - segundo ela, desde 1967, na redação da revista em que publicava o texto. Basicamente, compara a grandeza das atitudes e a riqueza da fala do cineasta com o vulto do país que representava sem provincianismo. Afinal, Glauber estaria sempre atento ao processo cultural mais amplo no qual se inseria como la bête du tiers-monde, como se definia de forma risonha o cineasta, segundo o testemunho da amiga. No texto, a importância da presença do cineasta no contexto cinematográfico local é valorizada ao extremo, e a autora incita o leitor a identificá-lo como agente decisivo na alteração profunda pela qual passara esse cinema em 20 anos. É possível entrever que os elementos finais para o cálculo dessa determinação sejam extraídos da convivência entre "crítico cineasta" e "crítica estrangeira", em Paris, no período de enfermidade que precedeu ao falecimento daquele. Pierre desfila alguns casos, contados na forma de crônica e costurados por reflexões e comentários. Anotemos esse importante aspecto do texto: de dispor do lado fragmentário, contra o vetor impossível da narração que pretende ter começo, meio e fim, ao mesmo tempo em que transmite uma autêntica experiência.

O texto abaixo está próximo do final do escrito, após toda a explicação sobre o contexto local, os cineastas e os filmes, intentando situar o leitor não familiarizado com o panorama de uma cinematografia moderna que construíra seus próprios dilemas. É uma espécie de síntese, bastante significativa em vista da enumeração ao estilo do personagem enleado:

Se, apesar de tudo, é preciso então reconhecer o papel de liderança de G.R. dentro do movimento cinemanovista, eu diria que por causa dele (em torno, com, contra, antes/durante/depois) se constituiu um corpo do cinema brasileiro: uma realidade orgânica, intelectual e física, uma 
anatomia, uma erótica, uma potência/impotência, um autorretrato e um retrato de família, uma árvore genealógica, ódios fratricidas e um movimento de amor sem precedentes, uma vida/morte/renascimento que o atravessa de uma ponta a outra (Pierre, 1981, p. 12).

A fatura do artigo se dirige para essa enumeração conclusiva após explicar o desejo do cineasta de um cinema livre, "verdadeiro" e “descolonizado", um cinema empenhado, enfim, na "autêntica expressão de um povo" - através de um cinema "artisticamente e economicamente adulto". Tais vetores são articulados, entretanto, na mesma circunvolução de um projeto cuja energia se investiu de uma reflexão de alcance global, sobre a totalidade do problema cultural e sociopolítico do brasileiro, terceiro-mundista, latino-americano, universal. Um pensamento conduzido pelo trabalho cuja questão de fundo é a mesma:

cineastas brasileiros que nós somos, qual é a especificidade de nossa mensagem e em quais condições nós podemos produzir, difundir, refletir, vender, impor ao mundo uma cultura cinematográfica inédita que nada poderia esmagar, alterar, banalizar ou corromper, nem de dentro nem de fora, o caráter de expressão autêntica de um povo? (Pierre, 1981, p. 9).

Não é o caso, aqui, de resgatar todo o curso do texto de Pierre. É de notar o tipo de asserção que reverbera o olhar internacionalista, mas aferrado à pontuação das especificidades locais, de um modo tão ao gosto do diagnóstico que apareceu em Cinema: trajetória no subdesenvolvimento, ensaio publicado por Paulo Emilio em 1973. Como veremos, o próprio Glauber Rocha compreendia Paulo Emilio de acordo com essas balizas, apesar de este não ter se utilizado de expressões como "autenticidade" e "verdade". Entretanto, o cruzamento de referências também é direto, não se restringindo ao tipo de diagnóstico e à forma de encarar, muitas vezes atravessada, o desafio de uma compreensão ampla. A proposição apenas indireta, pela forma do diagnóstico, seria talvez vaga se o intuito aqui fosse demonstrar um trânsito de idéias e alusões mútuas. Mas a palavra de Paulo Emilio Salles Gomes comparece no texto de Sylvie Pierre, sem menção de fonte, com o objetivo mesmo de compreender a fulguração do cineasta: um homem que profetizava. 
Com essa definição, alinhamos em perspectiva o artigo da crítica francesa com o prefácio intitulado Nota aguda, escrito por Paulo Emilio Salles Gomes para o livro Glauber Rocha, texto publicado em 1977 pela editora Paz e Terra, sob auspícios e incentivo daquele e de Raquel Gerber, contendo ensaios históricos e analíticos de vários estudiosos sobre o cineasta e a sua obra. ${ }^{3}$ O prefácio saiu em defesa da necessidade de prestar mais atenção ao trabalho então atual do cineasta e crítico, naquele momento desconhecido e restrito à publicação em revistas estrangeiras, com filmes ainda não vistos no Brasil - o caso citado é de O leão de sete cabeças (1970). Havia a dificuldade de acesso às obras. Enquanto se esperava por elas, o contato ficava restrito a roteiros ou "telegramas truncados que a imprensa de Golias publica ou textos glauberianos turbulentos que a de David edita." A nota do crítico segue explicando: "A referência bíblica desusada tem o mérito de aludir à exigente formação protestante de Glauber seguida de seu mergulho na religiosidade popular e delirante do Terceiro Mundo arcaico" (Gomes, 1977, p. 9). Esse seria o primeiro dado trazido à discussão no prefácio.

A passagem citada, além de situar de chofre um problema de cunho estético-ideológico, da formação ecoando o projeto de obra, acertou sem querer o seu petardo no centro da polêmica de enfrentamento entre Glauber Rocha e alguns colaboradores de Movimento, que definitivamente tomaria lugar a partir de uma acusação de censura feita pelo cineasta contra o jornal da imprensa alternativa. Os grandes periódicos, na época, davam destaque para as altissonantes declarações de Glauber Rocha sobre os militares, o direcionamento político-institucional do país e as acusações contra os seus inimigos (imaginários ou não). Isso se clarifica mais adiante, no quarto e quinto "dado" da Nota aguda, quando Paulo Emilio acrescenta a "experiência impessoal":

Glauber alude com frequência a escritores, politicos ou generais e ao fazê-lo os descondiciona do mundo real para transformá-los em peças de um imaginário particularizado. Mas atenção! Quando a imaginação glauberiana trabalha no genérico aí ela se enraíza na realidade. (...) Tanto os afetos quanto os desafetos são capazes de montar um elenco notável de seus absurdos. O resultado do acúmulo é sempre o mesmo: as evidências de insensatez acabam testemunhando um cintilante equilíbrio (Gomes, 1977, p. 9).
3. Ver as cartas enviadas por Paulo Emilio a Glauber em junho de 1974 e abril de 1975 (Bentes, 1997, p. 487488; p. 518-520) e a resposta de agosto de 1974 (p. 497-499), além das missivas para Raquel Gerber, de julho de 1974 e setembro de 1975. (p. 493-496; p. 531-533). Ver também a troca de cartas de janeiro de 1976 (p. 493-496; p. 531-533), com Glauber de Moscou e Paris e Paulo Emilio de Águas de São Pedro, nas quais um fala do cinema "soviético "russo" e outro, do retorno ao trabalho de conservador da Cinemateca Brasileira, indicando o início de um acerto para a guarda dos filmes (p. 577-589). 
A reflexão programada dentro do par realidade-imaginação é uma constante dentro dos textos de Paulo Emilio, como pode ser verificado também no diálogo com outro constante interlocutor, o crítico e cineasta David Neves. As observações acima relacionadas já argumentam sobre a tese de que o cineasta, desde Deus e o diabo na terra do sol (Glauber Rocha, 1964), era percebido como uma espécie de profeta. A enumeração tem como meta, portanto, emoldurar a definição que depois ganharia intensa reverberação - a de o cineasta ser um "Profeta Alado" - , não sem a seguinte ressalva:

Profeta não tem a obrigação de acertar, sua função é profetizar. Através de filme, escrita, fala e vida, Glauber tornou-se uma personagem mágica de quem não é fácil ser contemporâneo e conterrâneo. Ele é uma de nossas forças e nós Brasil a sua fragilidade (Gomes, 1977, p. 9).

Essa derradeira observação, da inexorável reunião entre "força" e "fragilidade", de figura e país, aparece ipsis litteris, com fonte mencionada, no mesmo número da revista Cahiers du Cinéma que trouxe o texto de Sylvie Pierre. O eco está no texto Dieu et le Diable à l'âge de la terre en transe, de Gustavo Dahl, a propósito de A idade da terra (Glauber Rocha, 1981). O texto de Dahl, inicialmente publicado em português no Jornal do Brasil de 25 de novembro de 1980, deixa mais evidentes os tipos de circulação e espelhamento implicados no artigo de Sylvie Pierre: o retorno invertido de Paulo Emilio sob a imagem refletida de Glauber Rocha.

\section{Sob a lente do mestre e um livro tagarela}

Da mesma maneira, David Neves trouxe o texto da Nota aguda à baila em sua Nota-crônica, prefácio da primeira edição de Revolução do Cinema Novo. Igualmente de redação fragmentada, o texto recupera trechos inteiros de Revisão crítica do cinema brasileiro, livro de Glauber lançado em 1963, para tentar explicar um "tipo muito particular de dialética existencial que preside a arquitetura 'dramática' da obra mais recente, 'manancial de gêneros' que evolui entre o ensaísmo e o texto "decidido e didático"” (Neves, 2004, p. 520). A ideia de um livro “meio bíblico”, segun- 
do a classificação de Neves, liga-se indiretamente à nota de apresentação do livro sobre Glauber Rocha escrita por Paulo Emilio. Entretanto, quando traz essa definição, o texto já havia mencionado o prefácio "memorável”, que Neves entende como "espécie de 3 x 4 holográfico que redime um pouco do tom "universitário"” adotado nos artigos dentro do livro, como faz questão de pontuar criticamente. Sobre o outro lado, do modo como Glauber mostrava Paulo Emilio, fala em ampliação tridimensional, em cortes e planos diversos ("épura”), do livro Revolução do Cinema Novo, da figura glauberiana fixada pela representação de Paulo Emilio (“approach"), atando a figura de um ao desenho esboçado por outro (Neves, 2004, p. 519).

Apenas para fechar um círculo de desdobramentos, lembremos também o texto de Alexandre Eulálio Rocha no meio do caminho, organizado entre outros no Livro involuntário, no qual o autor também se reporta ao prefácio Nota aguda para explicar como deveríamos nos postar diante do inevitável tête-à-tête com a singularidade intelectual glauberiana:

que - não dá para ignorar, desejemos ou não - se encontra bem no meio do caminho da nossa vida intelectual, pulsante. Ao abrir com esforçada "Nota aguda" de barítono quase-baixo uma obra coletiva sobre este cineasta incômodo, Paulo Emilio Salles Gomes exigiu de nós toda a cumplicidade não paternalista a fim de enfrentarmos o pedrouço eriçado da imaginação glauberiana (Eulálio, 1993, p. 301).

E como fica a imagem de Paulo Emilio desenhada por Glauber? Sem dúvida nenhuma, esse desenho foi esboçado no livro Revolução do Cinema Novo. Tal material emergiu de um esforço de arrumação - entornar o baú, remexer os papéis e pôr a casa em ordem - em sentidos diversos: 1) de fato, com Glauber organizando seus escritos em vista da execução de vários projetos de livro, que incluiria ainda O século do cinema e Roteyros do terceyro mundo; 2) enquanto projeto, buscando recuperar um impulso de aglutinação após anos de combate, a fim de realizar uma reconciliação com os seus, não só indulgente mas também crítica; 3) em termos de vivência pessoal, tateando uma síntese histórica, no viés de construção da memória. A antologia dedicada ao cinema brasileiro centra fogo na problematização do Cinema Novo, sendo composta de textos publicados aqui 
e acolá, desde 1959, entre artigos, entrevistas e debates revisitados, além de uma redação atual que se encarna na parte localizada mais ao final do livro, que é o principal esteio da memória reflexiva. Tal entrecho é o que nos interessa mais de perto.

"Livro de compilação? Talvez. Livro de montagem? Muito provável”, escreve David Neves, no início do prefácio Nota-crônica supracitado, travestindo seu próprio escrito com o caráter dramático que é um dos pilares de Revolução do Cinema Novo. Indubitavelmente, um livro desmedido e tagarela, contraditório testemunho de idas e vindas, principalmente se justapomos a escrita de período mais recente - a parte final, grosso modo - ao cotejo paciente das fontes mais antigas, de período anterior.

O último texto mencionando Paulo Emilio, nas páginas de Revolução do Cinema Novo, é também no trecho final, uma transcrição da entrevista "Estão confundindo minha loucura com minha lucidez 8o" (Rocha, 2004, p. 495-500), ao jornal O Estado de S. Paulo, bem enraizada nas conturbações do momento final de vida do cineasta, do difícil entendimento com colegas. Ele responde a críticas ao seu filme A Idade da terra, e é provocado a falar sobre os críticos a partir de um gancho trazido pelo entrevistador, de uma recente declaração de Chico Buarque de Holanda, que teria "criticado a crítica”. Há aqui o impulso de testemunho e diagnóstico de época, cuja descontinuidade histórica com o momento anterior é bem ressaltada, dada a pouca idade do declarante e dado o desfile de nomes - ele parece ter vivido em um outro mundo, de paradigmas muito distantes daqueles que ele deplora como presentes na redação dos jornais. Vejamos:

Com o processo de abertura no Brasil se verificou que vários críticos adotaram uma posição de censores. Ocorre um problema na redação dos jornais. A crítica de música, literatura, cinema, artes em geral é uma crítica especializada. Anteriormente as críticas eram feitas por homens como Álvaro Lins, Otto Maria Carpeaux, Almeida Salles, Paulo Emílio Salles Gomes, Sábato Magaldi. Grandes intelectuais eram os responsáveis pelas críticas nas várias áreas. No momento há uma decadência no setor. Parece que os chefes de redação destacam para as seções de crítica novatos e recém-chegados, despreparados, muitos deles desconhecedores do processo histórico das artes (Rocha, 2004, p. 498). 
A mesma constatação pode servir para atacar ou defender os críticos "antigos", entre eles Paulo Emilio, pois, se houve a decadência, por outro lado, havia a especialização. É uma faca com os dois gumes afiados: grandes intelectuais conhecedores do "processo histórico das artes", contudo direcionados para as suas especialidades. O gume benevolente destaca e nomeia, aqui, as figuras intelectuais, mas o lado envenenado está igualmente afiado e já vinha cortante durante todo o arco histórico examinado. É precisamente a agitação dos dois lados que toma conta de Revolução do Cinema Novo quando o cineasta fala do crítico.

Preto e branco, claro e escuro, moderno e arcaico, Roberto Pires e Paulo Emilio, Walter Clark e Zé Celso. O acerto de contas de Glauber frente aos seus desencontros com Paulo Emilio entra nesse sistema de oposições, que, de início, pode parecer simplificador, mas que serve muito bem e didaticamente para somar e diminuir os fatores.

Entre Walter Clark (como Roberto Pires) e Zé Celso (como Paulo Emílio) é o choque entre Brazyl moderno e Brazyl arcaico. Um que fala a linguagem da economia e da técnica e outro a comunicação ético-estética diluindo-se liter-teatralmente na revolução implosiva do Meio que se transforma em mensagem reprogramada pela miséria nacional - dialética de Bye-bye Brazyl. Grave foi o desencontro entre Roberto e Paulo como é deficitária a des-coordenação entre Walter e Zé (Rocha, 2004, p. 468-469).

Apesar da aparência, o livro-caixa dos mal e dos bem afamados não se reduz a um polo ou outro no caso de Paulo Emilio - figura simbólica do mestre, como a crítica já observou mais de uma vez; não há, inclusive, um saldo final deficitário ao longo do livro. Entretanto, são as últimas páginas que produzem o fator negativo do produto, fundamentalmente através da comparação de Gomes com Pires. O trecho "Pires Roberto 80" fala tanto de um como de outro, e até mais de Paulo Emilio. É longo, contraditório, mas explicita broncas antigas de Glauber, desde a possibilidade de colaboração em filme, em 1962, passando pelo estremecimento da não afirmação clara do Cinema Novo, por Paulo Emilio, nos anos seguintes, chegando ao rancor quanto à classificação da posição dos cineastas cinemanovistas como "ocupantes" dentro do pano- 
rama de Cinema: trajetória no subdesenvolvimento. Enfim, para utilizar sua própria forma de se definir: "Graças a Marcel Proust posso vislumbrar algumas raízes enfartais de Paulo através de uma trip com Roberto Pires" (Rocha, 2004, p. 460). O lado positivo das considerações sobre Paulo Emilio lastreia a própria presença corporal do crítico, figura de proeminência entre os jovens amigos na "antiguidade", além da admissão da importância das cortantes ideias que circularam desde a intervenção no Suplemento literário, especialmente as teses da I Convenção Nacional da Crítica Cinematográfica de 1960 (Gomes, 1982).

O texto se inicia com um elogio a Roberto Pires, seguido do seguinte parágrafo:

Vivesse Paulo Emílio Salles Gomes e teria em Roberto Pires tema para sua tese sob a via cultural brasileira (ocupada) contra a via cultural estrangeira (a ocupante - daí a nova lei para estrangeiros no Brazyl) cuja discussão deve ser remontada para que não se desenvolva a reacionária ideologia de que o cinema novo executa a Ocupação de um "outro" Cinema Brasileiro, como se os libertadores de ontem fossem ditadores de hoje, maniqueísmo dos intérpretes desfocados pela neurose ocupacionista de São Paulo nos sertões (Rocha, 2004, p. 459).

Então, o artigo de Argumento é o primeiro a ser mencionado, de forma francamente ácida, pois ali se diz potencial o desenvolvimento de uma "ideologia reacionária”, de "maniqueísmo" causado por "neurose ocupacionista", sob acusação de desfoque de identificação do oposto - os libertadores interpretados como ditadores. Sublinhamos os signos desfavoráveis com o objetivo de deixar claros o direcionamento do petardo e o tipo de explosão de ressentimento gerada. O parágrafo seguinte desliza e revela o salto para um passado ainda mais distante, inserindo um elemento a mais, que seriam "os sucessores do mestre", infelizmente não identificados. Quem seriam?

O retumbante sucesso de A grande feira (1961) em Salvador desmente a tese de Paulo Emílio segundo a qual o cinema novo "não se integrou no corpo nacional" ou que "nunca penetrou no público", ou "nunca deu dinheiro", expressões codificadas pelos sucessores do 
Mestre. Paulo Emílio teve relação contraditória com o cinema novo variando numa balança intelecto-sentimental, economia nos elogios e exacerbação das crises. Pai de Gustavo Dahl e Jean-Claude Bernardet e admirado pelos discípulos fanáticos, Paulo foi aprisionado pela rede dos acontecimentos cinemanovistas que revolucionavam o cinema internacional.

O teórico desconfiava de qualquer antiteoria e os progressos do cinema novo não o convenciam de novas safras. Atacando o Ocupante com olhos de Ocupante, Paulo reprimiu o cinema novo dos Ocupados. Ainda feto, escrevi cartas a Paulo anunciando o cinema novo com argumentações irrefutáveis e mesmo assim o empréstimo cultural veio a prazos curtos e juros altos (Rocha, 2004, p. 459-460).

Da simples acusação, o texto desliza para o ano de 1961 e resolve balancear os juízos, procurando explicar melhor as coisas ao leitor e nomeando alguns dos atores envolvidos na peça. Esta ideia de "relação contraditória" nos despertou o interesse para a execução de um projeto de estudo para a redação deste texto; foi a ignição da vontade de entender a oscilação discursiva, articulando os diversos sentidos envolvidos nesses deslocamentos de referências. E também para recusar algumas das palavras psicologizantes de Glauber Rocha, utilizadas no decorrer do artigo para explicar as razões do crítico e de suas escolhas: Paulo Emilio é visto como um "personesquizofrenado" que sofria com o insucesso dos amados cineastas; "tocado pelo milagre baiano nas carnes de Dina Scher", "ressurreição erótica" dada a partir da identificação de Luíza Maranhão em A Grande feira (Roberto Pires, 1961); "convertido", "apaixonado", atirado numa "espiral erótica"; educador sexual dos jovens cinemanovistas. Não continuaremos com esse desfile.

Mais importante é a exposição de outra reminiscência, mais ancestral, matriz do desajuste que atravessa todo o texto e toca os dois personagens principais do drama: o convite de Paulo Emilio a Glauber para dirigir um roteiro que havia escrito, "Dina do cavalo branco". Glauber declinou o convite e o incitou a dirigir o próprio roteiro. A resposta de Paulo Emilio também é negativa, e a sua justificativa a propósito de "negócios e técnicas" acaba virando uma obsessão de "Pires Roberto 8o", sendo também o elo de amarração entre Pires e Gomes. Vejamos o relato-comentário: 
Eu estava na Líder Laboratórios no final de 1961, montando Barravento, quando Paulo me telefonou do aeroporto Santos Dumont, onde minutos depois o encontrei radiante. Tirando duma pasta o roteiro de Dina do cavalo branco, falou que o escrevera para ser dirigido por mim e que tinha mais projetos, entre os quais uma peça para Flávio Rangel. O subdesenvolvimento matou Paulo Emílio. O Ocupado subdesenvolvido pelo Ocupante subdesenvolvendo-se impediu a práxis cinematográfica de Paulo. Depois de gostar e gozar com a leitura de Dina do cavalo branco, respondi que ele deveria dirigir o filme, mas negou-se veementemente, alegando que não entendia de "negócios e de técnica". Não entender de negócios e de técnica é uma neurose típica de intelectuais comprometidos com a visão aristocrática da produção artística, enquadrando os empresários e os técnicos como executivos das idéias impero-divinas. E Paulo era um Ymperador, a pessoa mais inteligente, culta e generosa do mundo, além de bonito e delicioso sob e sobre todos os aspectos, uma superstar, but... impotente para o cinema porque não conhecia "negócios e técnica" (Rocha, 2004, p. 460).

Como se vê, a balança realmente oscila, transformando-se em caldeirão, em que todos os fatos são ingredientes. Resumindo, o "maior crítico de cinema do Brazyl" (um "Ymperador") "não sujou as mãos" na "economia e na técnica" como Roberto Pires o fez. Todos os qualificativos favoráveis são exagerados, talvez para compensar as graves acusações. Glauber não assume, então, o ponto nevrálgico da dissensão. Fica evidente que a crítica de Glauber ao artigo de Paulo Emilio em Argumento, alvo das observações iniciais do cineasta, apenas aprofundou o desconforto já existente desde o desajuste que tomava lugar a partir do mítico encontro no aeroporto Santos Dumont. Produzindo um jogo de palavras, Glauber se via “ocupado" pelo crítico e escritor, "dos dez melhores da língua”, seu aprendiz até trocar de mestre ao conhecer Nelson Pereira dos Santos.

O que Paulo não compreendeu é que tanto o cinema novo da Bahya quanto o cinema novo do Nordeste paraybano e o cinema novo de Minas nasceram paralelamente ao cinema novo Carioca e ao cinema novo Paulista agitados por uma geração que explodiu nas páginas do Suplemento Dominical do Jornal do Brasil e em várias revistas regionais nos anos 60 - no Juscely-jan-janguismo: geração 
revolucionária em todos os campos e no cinema novo. Lembro-me de sua reação ao meu livro Revisão crítica do cinema brasileiro, (62 Civilização Brasileira, segunda edição aumentada revista para 1981)4, embora sua negação fosse tão entusiástica que as reticências eram superadas pelas demonstrações de afeto que o levaram a me emprestar seu ap. no Vale dos Sapos, onde, em 1964/65, vivi amores em São Paulo seguramente inferiores aos de Paulo na Bahia (Rocha, 2004, p. 462).

\section{0 fim e o princípio}

O feixe de referências e mútuas citações retoma, no final do ciclo do cinema moderno, os primeiros anos da relação entre realizadores e crítico. Essa sobreposição é muito indicativa da produção de ajustes e rememorações; a repetição dos processos aparecendo de modo sintomaticamente reiterativo. O exemplo cabal está no próprio texto da Nota aguda, se o comparamos com a resposta produzida por Paulo Emilio às menções e referências que Glauber Rocha fez constar no livro de 1963 , Revisão crítica do cinema brasileiro: “O livro de G.R é de G.R." (Gomes, 2004, p. 207). A observação, originalmente publicada no jornal Última hora, reverbera uma década depois. Afinal, se trata de uma experiência num nível que não é somente pessoal, mas de relação entre campos de força da crítica, apesar do dito em contrário:

Experiência pessoal. Glauber às vezes me cita e quase sempre o que me atribui não tem nada a ver comigo: passagens entre aspas não escritas nem faladas por mim, ideias eventualmente brilhantes que, diferentemente do que ele pensa, não são minhas infelizmente. Esses mal-entendidos não impedem - quase que diria pelo contrário que eu deseje e consiga estar muito próximo e ser um cúmplice dele (Gomes, 1977, p. 9).

Há, portanto, a remissão a momentos anteriores da relação, do mesmo tipo que o próprio Glauber Rocha efetivou em Revolução do Cinema Novo: são saltos no tempo que articulam o final dos anos 1970 e o princípio da década anterior, pontuados de passagem com conceitos do texto-síntese Cinema: trajetória no subdesenvolvimento,
4. A edição referida na citação não estava, de fato, em preparo. Uma nova edição só foi publicada em 2003 , acrescida de pesquisa das fontes e fortuna crítica do material. 
do final de 1973, mas curiosamente omitindo a reaproximação com Paulo Emilio, do ano seguinte, quando trocaram cartas e o crítico trabalhou com Raquel Gerber na organização do já mencionado livro Glauber Rocha, do qual consta a Nota aguda. As cartas desse momento omitido indicam uma atenção e uma dedicação particulares, de ambos os lados, uma proximidade gerada pelo projeto de livro, pela reunião de filmes do cineasta. Estamos em outro período da vida brasileira, sob as malhas da ditadura civil-militar instaurada há dez anos. Momento de reconciliação, como reconhece o ainda autoexilado cineasta em cartas enviadas a amigos mais próximos.

A nova matiz da relação, rearticulada sob o intermédio de Raquel Gerber, faz Glauber repor a importância de Paulo Emilio para as suas teorizações e traz à tona o outro momento de proximidade, também de troca de cartas, de 1960 a 1962. Glauber e Paulo Emilio se referem ao contexto de Barravento, da I Convenção da Crítica de 1960 e da passagem do crítico pela Bahia. Em especial, a carta de Glauber escrita de Roma, em agosto de 1974, é uma espécie de ressolidarização. Glauber tem aí a oportunidade de justificar a dedicatória inserida no começo de O Leão de sete cabeças (1970), feita ao crítico e mencionada na missiva: "Pena que você ainda não conheça o Leão. Se eu ganhar um dinheirinho aqui lhe mando de presente uma cópia $16 \mathrm{~mm}$. É o melhor presente que eu poderia lhe dar, o meu inconsciente determinou que o filme seria dedicado a você" (Bentes, 1997, p. 498).

Se são incontestáveis a presença e a importância das palavras do crítico Paulo Emilio Salles Gomes para o crítico e cineasta Glauber Rocha, também são cruciais as palavras daquele para defini-lo, por todos os lados, no período do final do ciclo moderno. Encontramos as repetições da definição do profeta alado nos mais variados escritos, em textos que cobrem uma gama de autores que inclui o embaixador Arnaldo Carrilho e o presidente José Sarney, como consta do livro Glauber Rocha, escrito por Sylvie Pierre e publicado na França em 1987. Essa mesma definição reapareceu, mais recentemente, reposicionada e incorporada do ponto de vista estético, no filme documentário, de registro poético e pessoal, Rocha que voa (Erik Rocha, 2002). Em especial, há a entrevista de Fernando Birri, na qual ele relata um sonho que teria como figura central, alada e de megafone na mão, um “anjo” Glauber Rocha na liderança de um cortejo de cineastas latino-americanos. 


\section{Bibliografia}

BENTES, I. (Org.). Glauber Rocha. Cartas ao mundo.

São Paulo: Companhia das Letras, 1997.

EULÁLIO, A. "Rocha no meio do caminho”. In: Livro involuntário: literatura, história, matéria \& modernidade.

Rio de Janeiro: Editora UFRJ. 1993.

GOMES, P. E. S. et al. "Debate sobre 'Revisão crítica do cinema brasileiro"'. In: ROCHA, G. Revisão crítica do cinema brasileiro. São Paulo: Cosac Naify, 2004. . "Nota aguda". In: GERBER, R. et al. Glauber Rocha.

Rio de Janeiro: Paz e Terra, 1977.

. "Uma situação colonial?" In: Crítica de cinema no

Suplemento Literário. Rio de Janeiro: Paz e Terra, 1982.

NEVES, D. "Nota-crônica”. In: ROCHA, G. Revolução do Cinema

Novo. São Paulo: Cosac Naify, 2004.

PIERRE, S. "Glauber Rocha, par cœur, de tête et dans un corps".

In: Cahiers du Cinéma. Paris, n. 329, 1981.

Revisão crítica do cinema brasileiro. São Paulo:

Cosac Naify, 2003.

ROCHA, G. Revolução do Cinema Novo. São Paulo:

Cosac Naify, 2004. 